\title{
sciendo
}

DOI: $10.2478 /$ rjti-2021-0003

ROMANIAN JOURNAL

OF TRANSPORT INFRASTRUCTURE

\section{ACCELERATED LABORATORY TESTING FOR REFLECTIVE CRACKING}

Mihai Gabriel Lobază, Lecturer Ph.D. Eng., Technical University of Civil Engineering Bucharest, e-mail: mihai.lobaza@utcb.ro

\section{Rezumat}

Una dintre cele mai utilizate metode de reabilitare a structurilor rutiere este așternerea unui strat asfaltic de protecție peste un beton de ciment degradat. Principala problemă a acestei soluții o reprezintă fisurarea reflectivă, mai precis transmiterea fisurilor existente din stratul inferior în îmbrăcămintea asfaltică.

Metoda prezentată în cadrul acestui articol presupune o încercare de laborator accelerată pe epruvete compuse dintr-o placă de beton prefisurat peste care se lipește o placă de asfalt, la solicitări echivalente traficului rutier. Această încercare permite observarea propagării fisurii din stratul inferior către stratul superior, până la cederea acestuia, prin intermediul unor parametri cum ar fi deformata epruvetei, deschiderea și lungimea fisurii în asfalt, dar și deschiderea fisurii existente în beton, raportate la numărul de cicluri.

Prin relaționarea acestor parametri se pot trage concluzii importante legate de comportarea structurii compozite la fisurare reflectivă, putându-se alege rețeta optimă a stratului asfaltic de protecție.

\section{Cuvinte cheie: fisurare reflectivă, parametrii fisurii, încercare accelerată.}

\section{Abstract}

One of the most used methods of rehabilitation of road structures is the laying of a protective asphalt layer over a degraded concrete. The main problem of this solution is the reflective cracking, more precisely the transmission of the existing cracks in the lower layer in the asphalt pavement.

The method presented in this article involves an accelerated laboratory test on specimens composed of a pre-cracked concrete slab over which an asphalt slab is glued, subjected to equivalent traffic loads. This test allows the observation of the crack propagation from the lower layer to the upper layer, until it yields, through parameters such as deformed specimen, opening and length of the crack in asphalt, but also the opening of the existing crack in concrete, relative to the number of cycles.

By relating these parameters, important conclusions can be drawn about the behavior of the composite structure at reflective cracking, being able to choose the optimal recipe of the protective asphalt layer.

Keywords: reflective cracking, cracking parameters, accelerated test. 


\section{ROAD MATERIALS FATIGUE DUE TO CYCLIC TRAFFIC LOADS}

The experimental research of the various load effects of road materials, combined with the behavioral phenomenological research at the level of material structure, represents an important activity in the field of road transport infrastructure.

This objective is further analyzed by experimental small-scale laboratory modeling of how the phenomenon of fatigue develops in a protective asphalt layer on a cement concrete coating with the service life consumed. In this case, the analysis of reflective cracking in the asphalt protection layer is followed by phenomenological simulation at the experimental model level, using equipment capable of tracking reflective cracking at cycles of stress assimilated to road traffic and with imaging acquisition of crack propagation through the asphalt layer.

The term structural fatigue is associated with the damage to repeated loading cycles of the connections between the road layer components (Ramsamooj \& Majidzadeh, 1973). This phenomenon starts with the appearance of microcracking, which by the accumulation of loading cycles develops in the form of open cracks or cracks in the road layer. The implications of the effect of structural fatigue are manifested by the reduction of the resistance of the respective material and by the reduction of the load-bearing capacity of the road layer.

In principle, the fatigue of a road material is recognized as a complex phenomenon, which cannot be easily explained from a theoretical point of view. Therefore, experimental tests to assess the structural fatigue of a material come to quantify the theoretical parameters taken in the phenomenological analysis.

The literature refers to the statistics of mechanical approaches to the phenomenon of fatigue for the explanation of the effects, by analyzing the problem based on the kinetic concepts of the mechanism of rupture, which means that the crack involves a structural rearrangement of road components due to cyclic traffic loads and temperature variations. Accumulation by concentration of stress at the crack leads to rupture of the material by loss of structural stability. This theory leads to a quantitative assessment of the results, but it lacks the considerations of microstructural, geometric mechanics and contour effects.

It was concluded that the phenomenon of fatigue is associated with the concept of rupture and structural instability. Fatigue has two stages, namely the initiation of the crack and its development until rupture (Elseifi \& Al-Qadi, 2004). These stages develop over time during the loading-unloading cycles. 
The process of initiating cracking and ending by the appearance of rupture differs from material to material. The development of the crack on the layer thickness is associated with the appearance of structural discontinuities and energetic variations in this area.

The structural discontinuity is equivalent to the plasticization of the material at the end of the crack which, by exceeding a certain limit, allows its development on the thickness of the road layer.

From this point of view, the existing theories accept the following stages of crack evolution (Figure 1):

- Energy accumulation in elastic behaviour

- Energy accumulation in plastic behaviour

- Energy accumulation at fracture

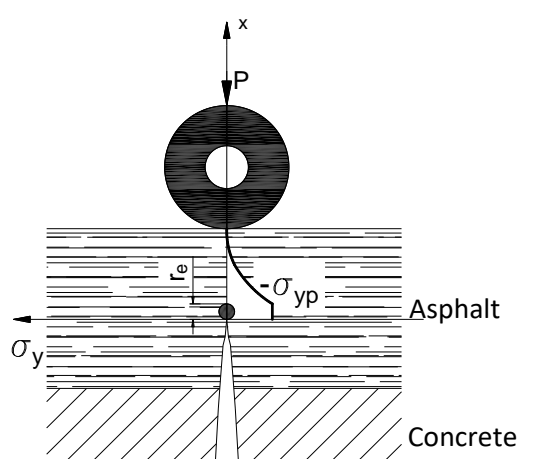

Stage I: Elastic (initialization)

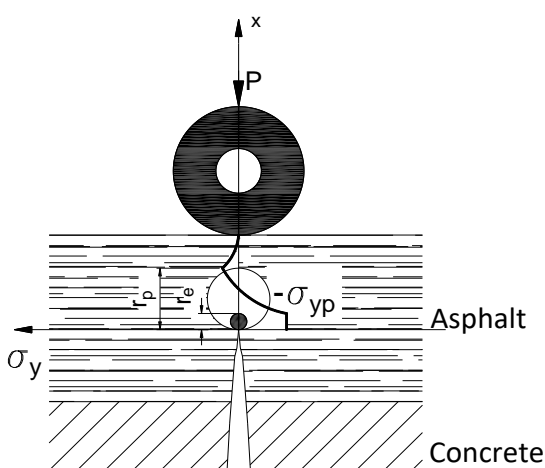

Stage II: Plastic (crack propagation)

Figure 1 Stages of cracking evolution

The mechanical explanation of cracking at load cycles was developed by Griffith theory (Griffith, 1921). Later Irwin and Kies (Irwin \& Kies, Fracturing and Fracture Dynamics, 1952) (Irwin \& Kies, Critical Energy rate analysis of fracture strength of large welded structures, 1954) propose to modify Griffith's theory by analyzing the state of tension in the road layer, by identifying plastic components that lead to crack development.

The fracture mechanics was demonstrated by Irwin by introducing a factor that expresses the intensity of the stress. Thus, he observed that three modes of developing the state of tension can be distinguished in the opening of the crack as a measure of the propagation of this phenomenon (Figure 2). 
ROMANIAN JOURNAL

OF TRANSPORT INFRASTRUCTURE

Mihai Gabriel Lobază

Accelerated laboratory testing for reflective cracking

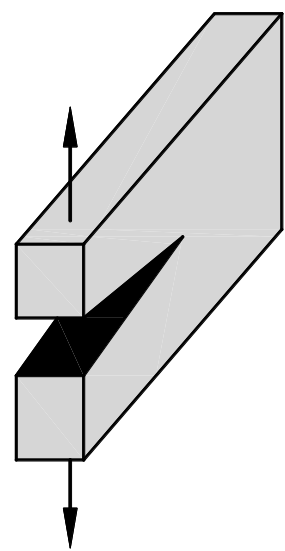

Mode I. Opening

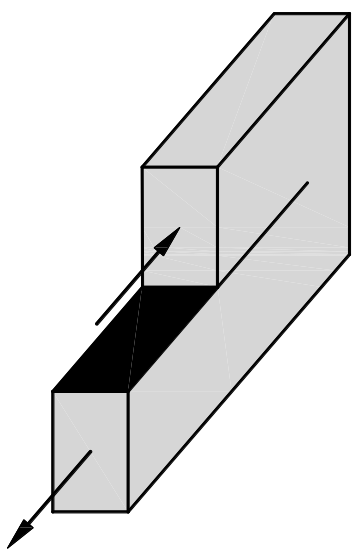

Mode II. In-Plane Shear

\section{Figure 2 Fracture modes}

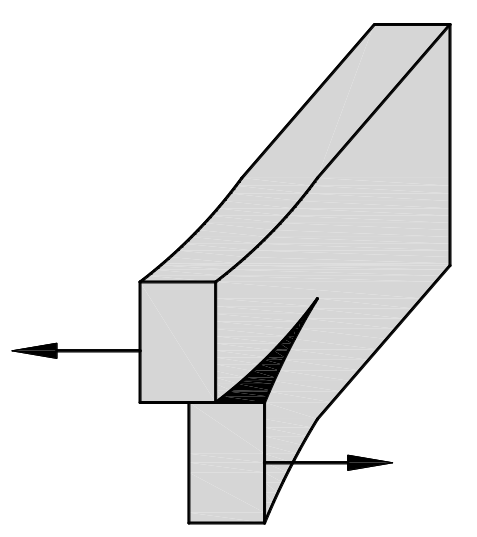

Mode III. Out-of-Plane Shear

The three modes are sufficiently explicit in the elastic stage. Each movement in the crack is associated with a stress field in its immediate vicinity (Figure 3).

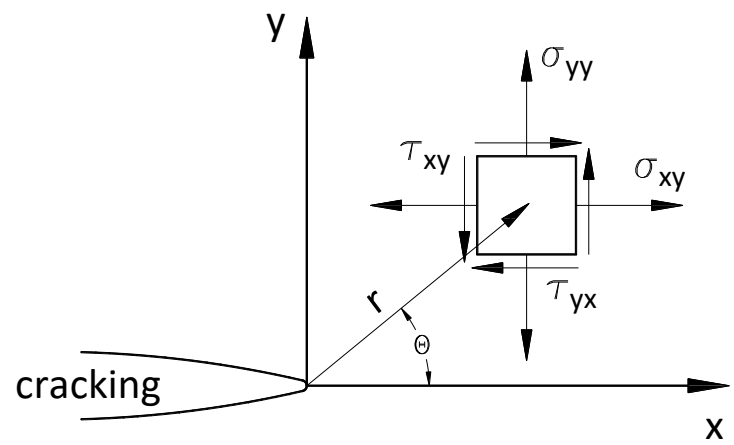

Figure 3 Stress field in the vicinity of the crack tip

Analytical modeling can be simplified by experimental research, which visualizes the evolution of the cracking process to cyclic stresses assimilated to road traffic.

This can be done in 3 ways, namely:

- Experimental sectors in the field (the results are obtained in years),

- Laboratory test tracks such as APT facility (Perez, Balay, Tamagny, \& Petit, 2007). This determination is made by approximating 10-20 years of stress in just 2 months of traffic loads.

- Experimental model in the laboratory, on a small scale, able to reproduce the phenomenon of reflective cracking (Yu, Lu, \& Yang, 2013) (Perraton, Guissi, Pierre, \& Dore, 2008). The duration of the tests is of the order of hours, days. 


\section{THE CRACKING DEVICE WITH TEMPERATURE CONTROL. THE PRINCIPLE OF TESTING METHOD FOR REFLECTIVE CRACKING}

The cracking device with temperature control is a prototype device developed within the Roads Laboratory of the Technical University of Civil Engineering of Bucharest. It is part of the latest mode of experimental research, namely a small-scale model.

To speed up the occurrence of the cracking phenomenon and the propagation of the crack under cyclic loads, loading steps were used, following the evolution of the deformation of the specimen in extreme stress conditions. Using constant loading cycles and equivalent stress steps, the optimal recipe can be determined by behavioral reporting in terms of the evolution of the cracking phenomenon.

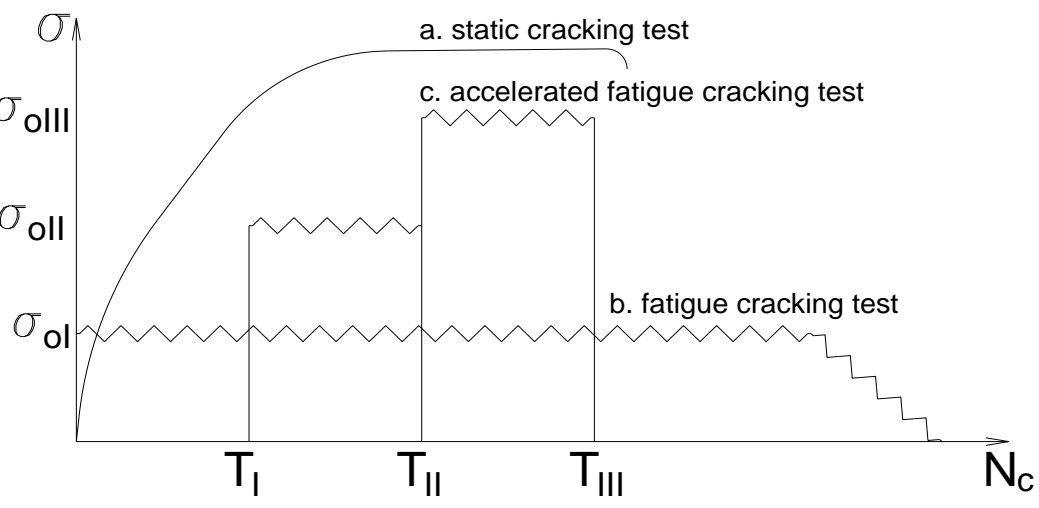

Figure 4 Types of fatigue tests

Figure 4 shows the test methodology related to well-known methods such as static cracking test and fatigue cracking test.

The fracture stress in accelerated regime (after the propagation of the crack on the thickness of the asphalt mixture sample layer), is obtained in a shorter time than the fatigue test and represents a characteristic equivalent for the dynamic test.

As presented in a previous article (Lobază \& Dicu, Experimental Modelling of Asphaltic Layers Behaviour at Reflective Fracture from Degraded Pavements - Parametric Studies, 2015), with the help of this device, the following parameters can be measured through the video acquisition system (Figure 5):

- $\quad w=$ deformation of the specimen (asphalt layer on pre-cracked concrete),

- $d b=$ existing crack opening in the old concrete,

- $e=$ detachment at the asphalt-concrete interface in the crack area,

- $f=$ crack length in the protective asphaltic layer, 
ROMANIAN JOURNAL

OF TRANSPORT INFRASTRUCTURE

Mihai Gabriel Lobază

Accelerated laboratory testing for reflective cracking

- $d=$ crack opening in the protective asphaltic layer.

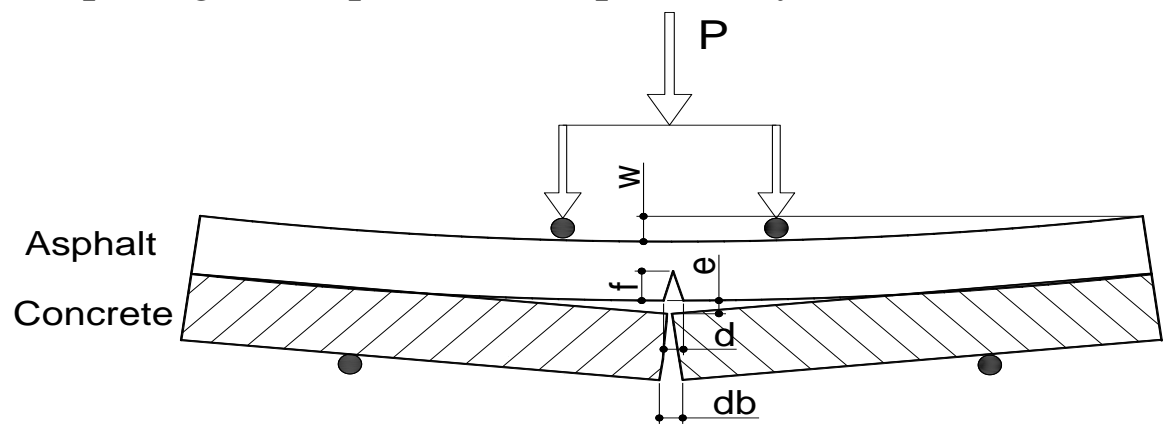

Figure 5 Reflective cracking parameters

Using this scheme of testing the reflective cracking of the pre-cracked concrete support in the protective asphalt layer, various behavioral interpretations of the composite road structure can be obtained. The proposed model is like the CTOD three-point testing model proposed by Anderson (Anderson, 2005) (Figure $6)$.

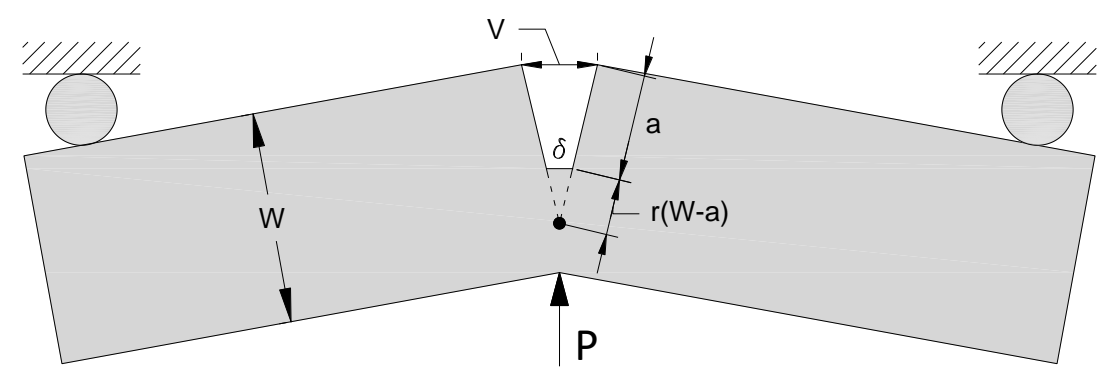

Figure 6 Experimental CTOD, three point bending test

\section{CRACK TRANSFER CAPACITY FROM CONCRETE TO THE ASPHALTIC PROTECTIVE LAYER}

Two of the parameters measured in the experiment, which indirectly influence the propagation of the crack through the asphalt protection layer, are: the initial opening of the concrete crack $\left(\mathrm{db}_{\mathrm{i}}\right.$, friction between aggregates and/or between cement stone, between crack walls), and the initial detachment of the asphalt layer from the concrete slab ( $e_{i}$, the bitumen bonding layer, at the interface between the concrete and the asphalt).

These are highlighted on the experimental model related to the cracking device in Figure 7, their values are presented by imaging the data generated by the software of the equipment according to Table 1. 
ROMANIAN JOURNAL

OF TRANSPORT INFRASTRUCTURE

Mihai Gabriel Lobază

Accelerated laboratory testing for reflective cracking

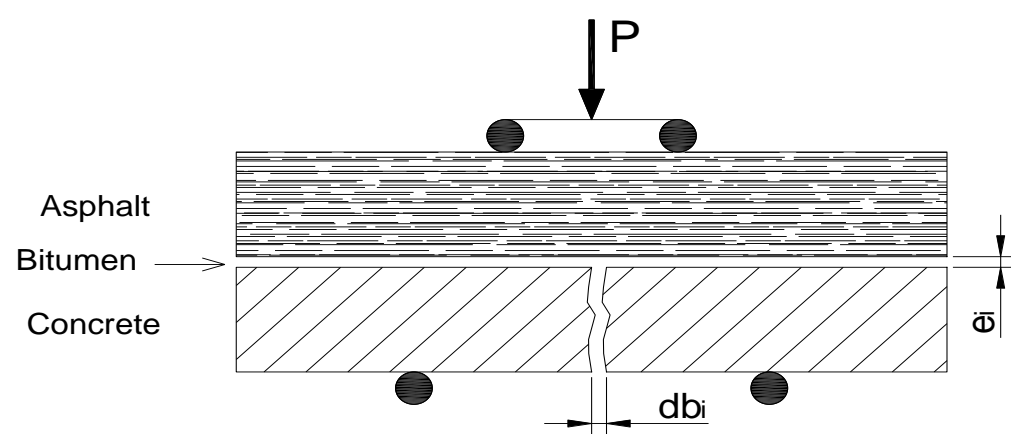

Figure 7 The initial parameters of the cracking

Table 1 The initial values of the concrete opening $\left(d b_{i}\right)$ and detachment $\left(e_{i}\right)$

\begin{tabular}{|c|c|c|c|}
\hline \multirow{2}{*}{ Specimen } & $\begin{array}{c}\text { Upper view } \\
\mathbf{d} \mathbf{b}_{\mathbf{i}}=\text { initial concrete opening }(\mathrm{mm})\end{array}$ & $\begin{array}{c}\text { Side view } \\
\mathbf{e}=\text { initial detachment of the asphaltic } \\
\text { layer from the concrete }(\mathrm{mm})\end{array}$ \\
\hline \multirow{3}{*}{$4 \mathrm{~b}$} & & & \\
& & 3.0088 & \\
& & & \\
\hline
\end{tabular}

The reflective crack appeared at the road surface, without being accompanied by the appearance of local settlements, presupposes that the propagation phenomenon occurs without the opening at the level of transfer loss at the concrete layer and then, the detachment parameter at the asphalt-concrete interface is practically zero, while when there are also settlements it is assumed that the transfer to the crack in the concrete support layer has been consumed and there are also interface detachments ( $e_{i}$ parameter).

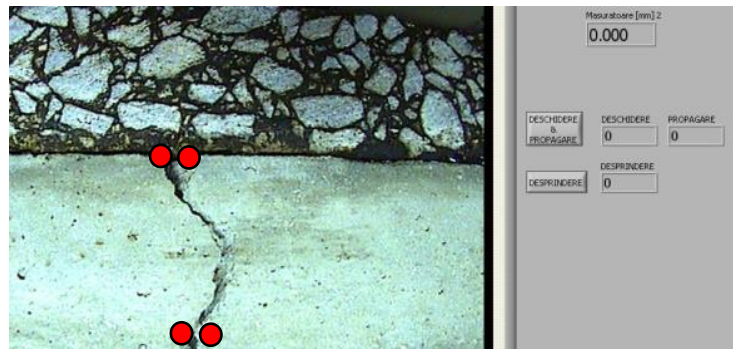

a. Slab with crack load transfer, Cracking in the specimen

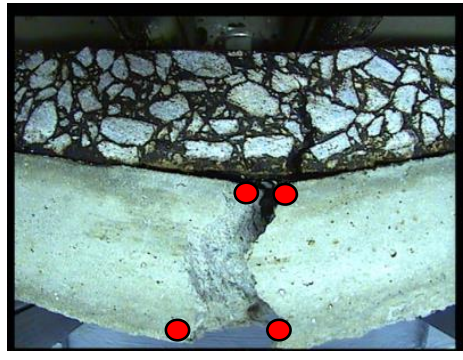

b. Slab without load transfer, Fracture in the specimen

Figure 8 Types of crack load transfer 
To be able to interpret the way the crack propagates through an asphalt layer of protection of a concrete pavement degraded by cracking, cracks that can be of various degrees of severity depending on their opening, an experimental study was performed on specimens, in the laboratory (Lobază \& Dicu, Anticipating the cracking process of asphalt pavements by experimental modeling in the laboratory, 2013). These differ from each other by the predetermined opening of the concrete crack.

The propagation time of the crack through the protective asphalt layer is determined indirectly by the number of cycles related to the cracking process and by the resulting vertical deformation $(w)$.

In the first part of the test, the pre-cracked concrete support has a relatively small, predetermined opening $\left(\mathrm{db}_{\mathrm{i}}=3 \mathrm{~mm}\right)$. This causes the 2 slabs to work together at the crack, with the ability to transfer the load from the traffic to the pre-cracked support (Figure 8a).

In the second part of the test, there was no load transfer between the 2 concrete slabs, the crack was transmitted to the asphalt slab (Figure 8b), and other parameters could be measured such as the opening $d$ and the length $f$ of the crack in the asphalt.

\section{PROCEDURE FOR INTERPRETING THE RESULTS OBTAINED FOR MODELING THE REFLECTIVE CRACKING}

The experimental tests performed showed 3 stages of propagation of reflective cracking (Figure 9) in the case of laying the protective asphalt layer over a pre-cracked concrete coating:

- Stage 1. The stress is transferred by the friction between the pre-cracked concrete slabs

- Stage 2. The concrete crack was transmitted to the protective asphalt (propagation)

- Stage 3. The crack reached the surface of the protective asphalt (opening and propagation through the asphalt) 
ROMANIAN JOURNAL

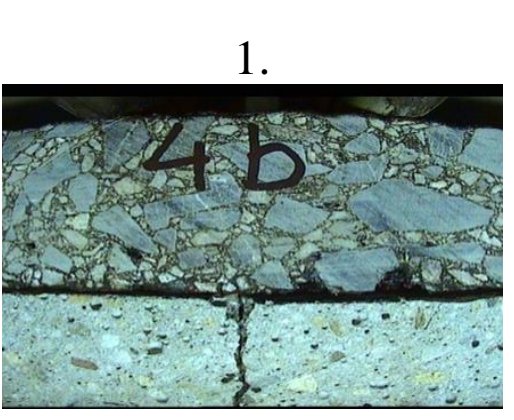

Number of cycles: $0-\mathrm{n}_{\mathrm{ci}}$ Vertical deformation: $0-\mathrm{w}_{\mathrm{i}}$ Asphalt Crack length: $\mathrm{f}=0$ Asphalt Crack opening: $d=0$
2.

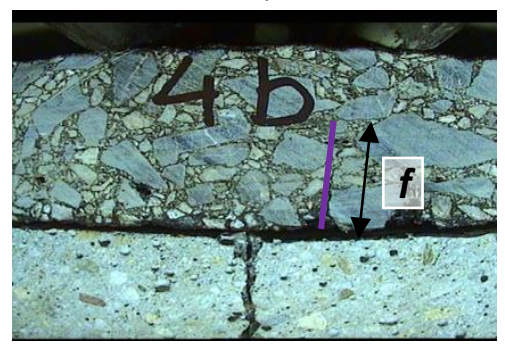

Number of cycles: $n_{\mathrm{ci}}-\mathrm{n}_{\mathrm{cf}}$ Vertical deformation: $\mathrm{w}_{\mathrm{i}}-\mathrm{w}_{\mathrm{f}}$ Asphalt Crack length: $\mathrm{f}=0-\mathrm{h}_{\text {asf }} / 2$ Asphalt Crack opening: $\mathrm{d}=0$

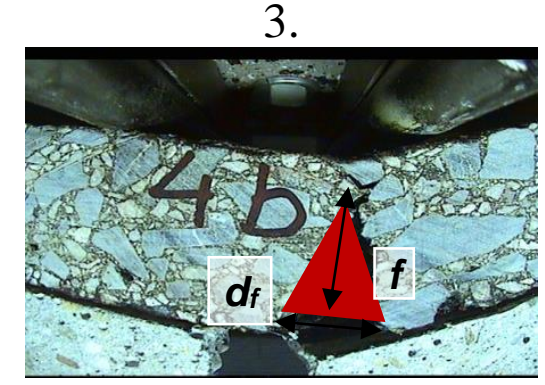

Number of cycles: $n_{\mathrm{cf}}-\mathrm{n}_{\mathrm{cR}}$ Vertical deformation: $\mathrm{w}_{\mathrm{f}}-\mathrm{w}_{\mathrm{fR}}$ Asphalt Crack length: $\mathrm{f}=\mathrm{h}_{\mathrm{asf}} / 2-\mathrm{h}_{\text {asf }}$ Asphalt Crack opening: $d_{f}$

Figure 9 Stages of reflective cracking

For the calibration of the mathematical model with the results obtained by experimental modeling on the cracking device, the following notations are used, following the research of the reflective crack:

- $n_{c i}$-number of cycles at the initiation and propagation of crack in the asphalt;

- $n_{c f}$-number of cycles at the opening and propagation of crack in the asphalt

- $n_{c R}$-number of cycles at the complete fracture of the specimen

- $n=\frac{n_{c f}-n_{c i}}{n_{c R}-n_{c i}} \quad$-for $n_{c f} \geq n_{c i}$;

- d exp-crack opening of the asphalt -experimental model;

- d calc-crack opening of the asphalt -mathematical model

- $\mathbf{f}$ exp-crack length of the asphalt -experimental model;

- f calc -crack length of the asphalt -mathematical model;

- db exp - existing crack opening of the concrete -experimental model;

- db calc - existing crack opening of the concrete -mathematical model.

The results of the research in this direction (Lobază, Contributions regarding the analysis by modeling the rehabilitated road structures at loads assimilated to road traffic, 2020), highlighted the following principles for evaluating the parameters of reflective cracking, as follows:

$>$ The measurements and processing of these parameters, the length and opening of the crack, for specimen $4 \mathrm{~b}$ indicate:

- The variation of the crack opening $d$, but also of the length $f$ in the asphalt layer, in relation to the increase of the number of cycles $n$, is nonlinear (Figure 10). The regression model that best describes this relationship is:

$$
y=\frac{a_{0} \cdot n}{1+a_{1} \cdot n+a_{2} \cdot n^{2}}
$$


- It can be determined how many cycles are needed until the crack propagation reaches half the thickness of the protective asphalt plate $(\mathrm{h}=50 \mathrm{~mm}): \mathrm{n}_{\mathrm{cf}}=1080$ cycles $(n=0.3$, or we can say that the crack length has reached $h / 2$, at $30 \%$ of its total propagation duration). This finding is extremely important in relation to other experimental models used in the evaluation of the fatigue phenomenon in asphalt layers, which establish that the strength of the layer is consumed if half of the deformation accumulated during the application cycles has been consumed.

The regression model found for the evolution of the concrete opening $d b$ in relation to $n$ isError! Reference source not found.:

$$
d b=\frac{a_{0} \cdot a_{1}+a_{2} \cdot n^{a_{3}}}{a_{1}+n^{a_{3}}}
$$

In Figure 10, the initial cracking resistance of the asphalt layer is higher, by the accelerated growth in the crack opening value $(d)$ and the slower evolution of the crack propagation $(f)$. It is also noted that the diagram of experimental phenomenological evolution is accurately represented by the related mathematical law.

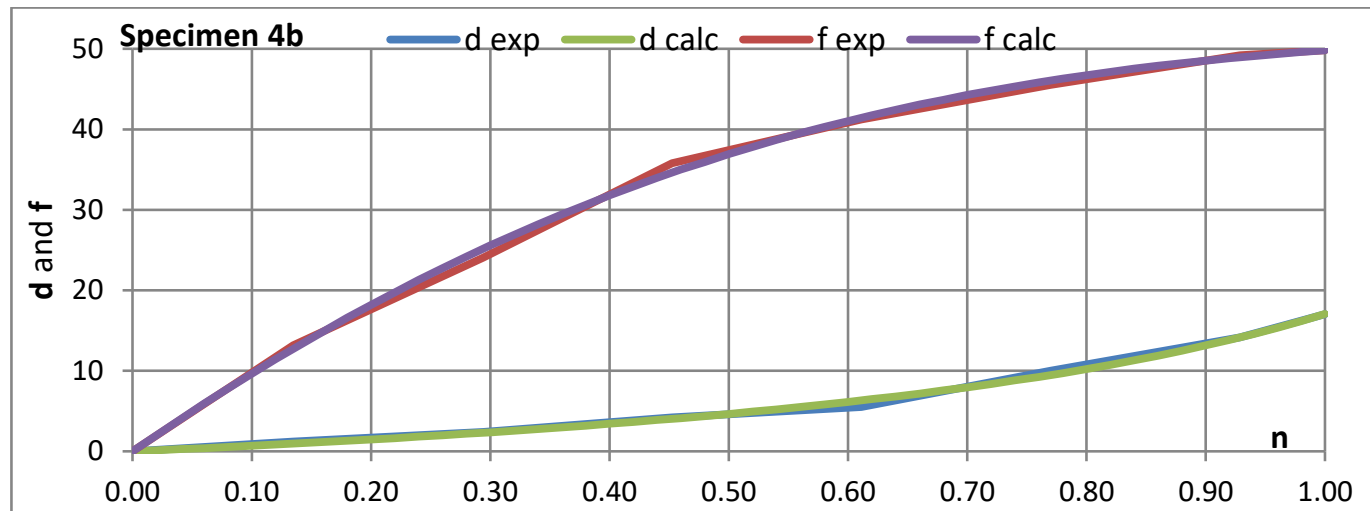

Figure 10 Crack opening $(d)$ and length $(f)$ in relation to $n$, specimen $4 b$

- The variation rates of the crack opening (Figure 11a), of the crack length (Figure 11b) through asphalt, respectively of the concrete opening (Figure 12), are calculated by deriving the functions, in order to obtain a mathematical law of parametric variation. 


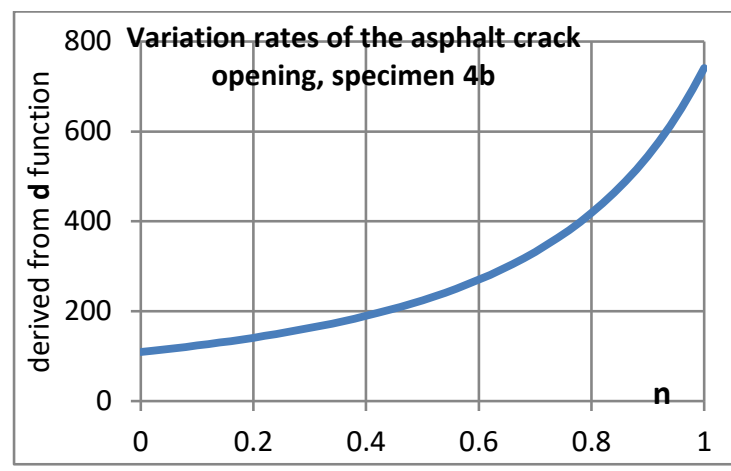

a. Asphalt crack opening $(d)$, specimen $4 \mathrm{~b}$

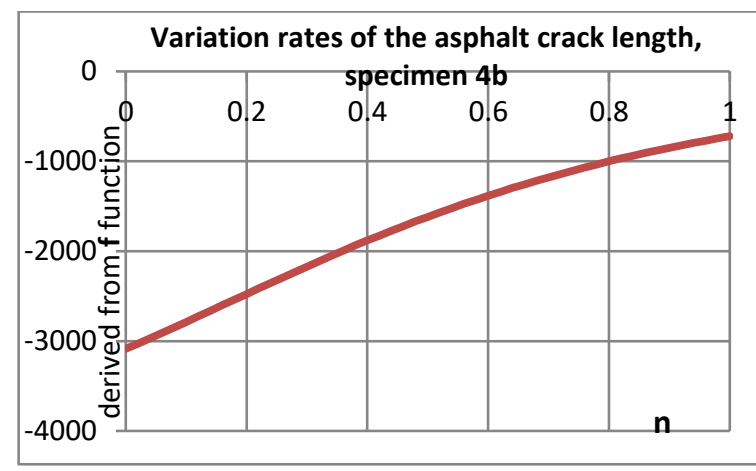

b. Asphalt crack length $(f)$, specimen $4 \mathrm{~b}$

Figure 11 Variation rate of the asphalt crack opening and length, specimen $4 \mathrm{~b}$

Depending on the curvature of the diagrams, the connection between the parameters of the reflective crack can be found, so if the variation rate at the opening of the crack in asphalt is lower, and at the end of the test the reflective propagation will increase rapidly, the variation rate of the crack length is more accentuated at the beginning of the test, fading towards the end of the test. This different behavior between the crack opening speed and its length, is explained by the rheological behavior of this road material and by the transition from elastic to plastic behavior during the development of local deformation in the "crack tip", according to Irwin's theory.

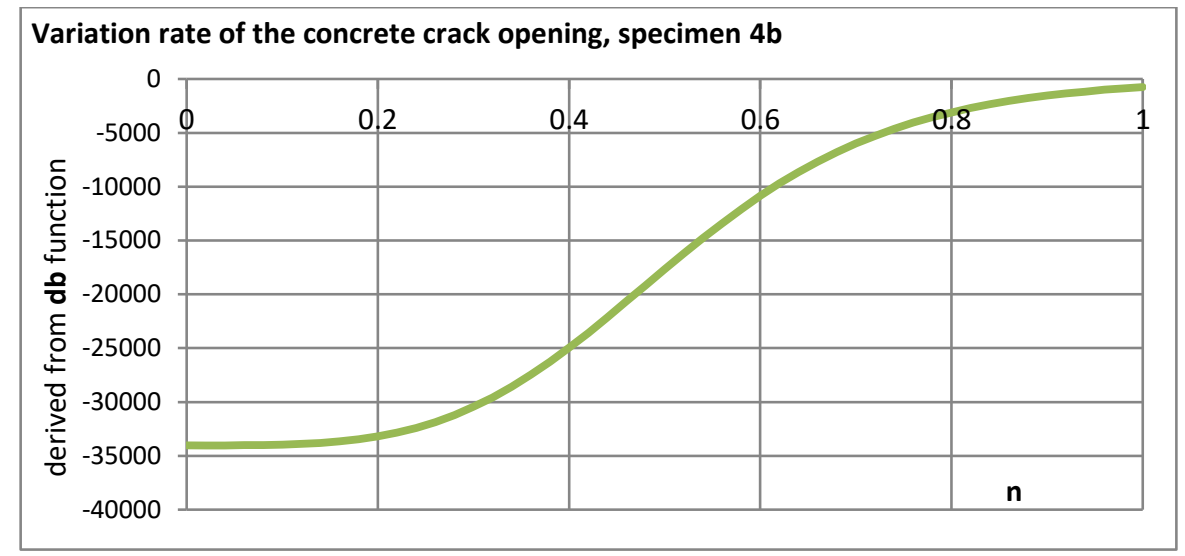

\section{Figure 12 Variation rate of the concrete crack opening, specimen $4 \mathrm{~b}$}

Figure 12 shows the phenomenon created by the transfer effect to the crack by the initial friction of the slabs of this support layer, attenuated by the damping of the transfer process by the presence of the asphalt layer to the upper fiber of the concrete layer, because of the technological bonding operation. Thus, initially, when the transfer of the crack in the concrete works together with the damping caused by the asphalt layer present at its surface, the capacity to take over the 
vertical deformation (deflection under load) is higher and therefore the opening speed of the existing crack in the concrete it is smaller.

In the intermediate stage, when the transfer of the concrete crack is consumed, the transfer capacity of the asphalt is mobilized. The curvature of the diagram changes, so that in the final phase of reflective propagation the crack opening speed of concrete to grow at a lower deflection.

\section{EXPERIMENTAL OBSERVATIONS REGARDING THE PARAMETRIC STUDY OF REFLECTIVE CRACKING.}

To highlight the parametric variations of the reflective cracking, interparametric influence analyzes can be made, to identify the evolution of the cracking process.

In a first scenario, it is possible to establish the variation of the crack opening speed depending on the increase of the fatigue load cycle of the material.

Thus, compared to a central axis, it can be seen from the diagram below that as the number of loading cycles assimilated to road traffic increases, the opening of the crack increases and implicitly the length of the crack in the process of propagation to the upper part of the asphalt layer. protection.

So, in this way, it is possible to anticipate by comparative study between several asphalt mixture recipes, the capacity of resistance to reflective cracking, respectively identifying the optimal mixture recipe for the asphalt protection layer at which at the same number of loading cycles, crack opening and implicitly its length on the thickness of the asphalt layer, is smaller in the sense of delaying the appearance of the crack at the starting surface.

Of course, at the observational level, it is possible to obtain the variation of the opening from the pre-cracked concrete layer, in the process of reflective propagation of the crack through the asphalt protection layer.

To explain the procedure for analyzing the results obtained from the interpretation of the data of reflective cracking, the tests are presented on 2 specimens ( $7 \mathrm{a}$ and $7 \mathrm{~b}$ ) prepared by cutting in half an asphalt slab and then bonded each with bitumen to the pre-cracked concrete. Thus, the following phenomenological evolutions can be observed: 


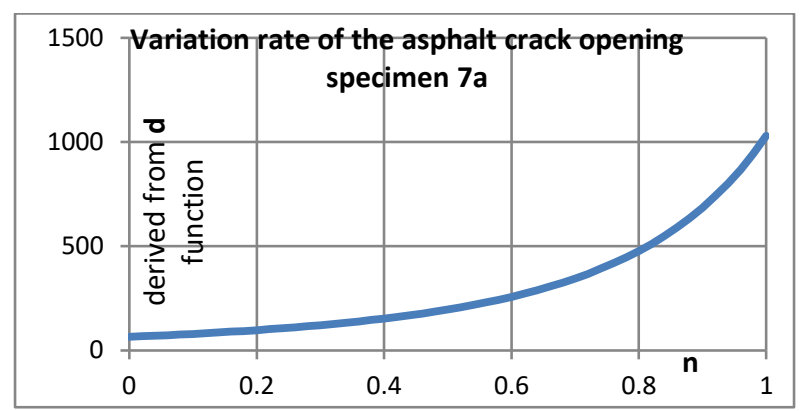

a. $\quad$ specimen $7 \mathrm{a}$

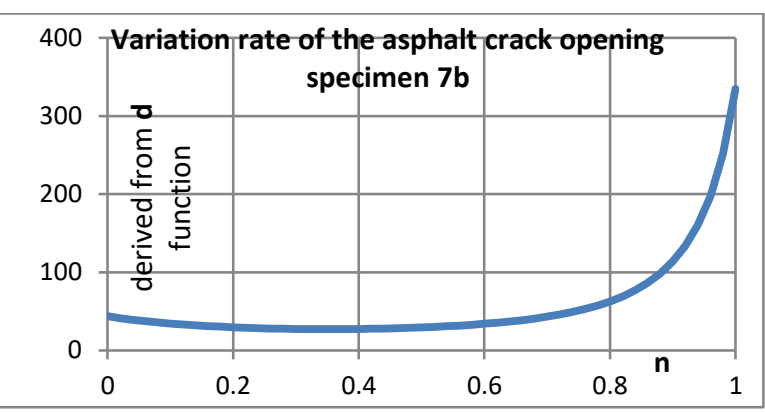

b. specimen $7 \mathrm{~b}$

Figure 13 Variation rate of the asphalt crack opening, specimen $7 \mathrm{a}$ and $7 \mathrm{~b}$

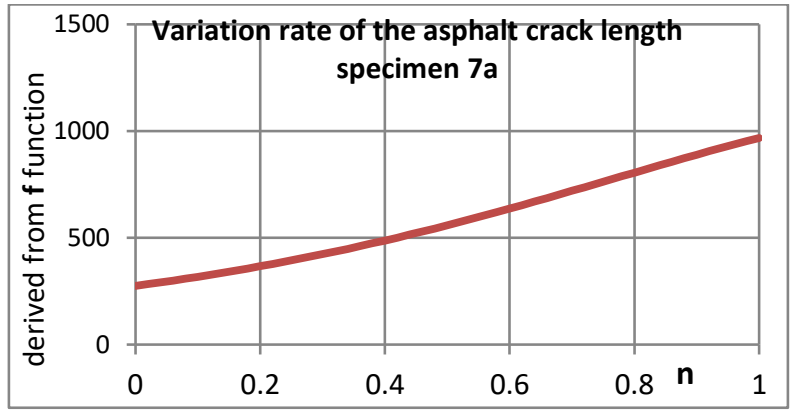

a. specimen $7 \mathrm{a}$

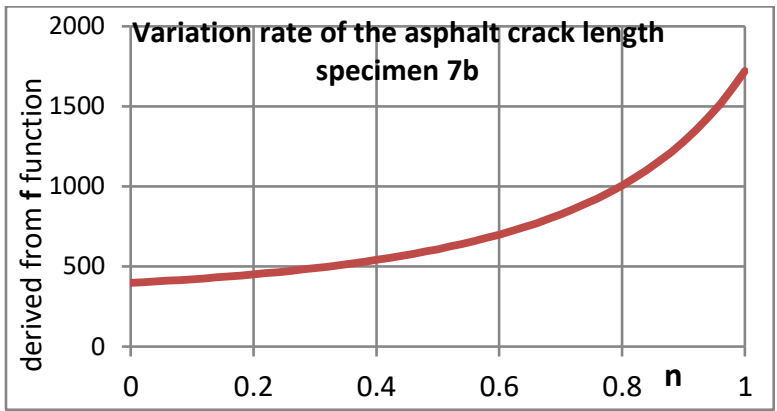

b. specimen $7 \mathrm{~b}$

Figure 14 Variation rate of the asphalt crack length, specimen $7 \mathrm{a}$ și $7 \mathrm{~b}$

-a proportional increase of the crack opening $d$ (Figure 13) with the loading cycles $n$, as well as a linear variation of the propagation speed of the crack length (Figure 14) in the last third of the asphalt layer thickness.

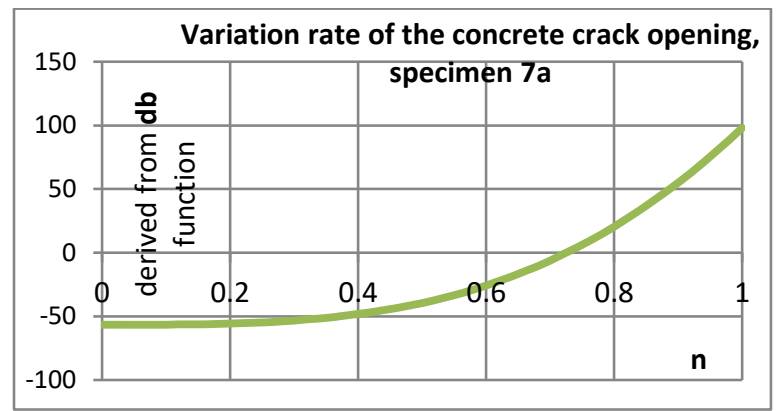

a. specimen $7 \mathrm{a}$

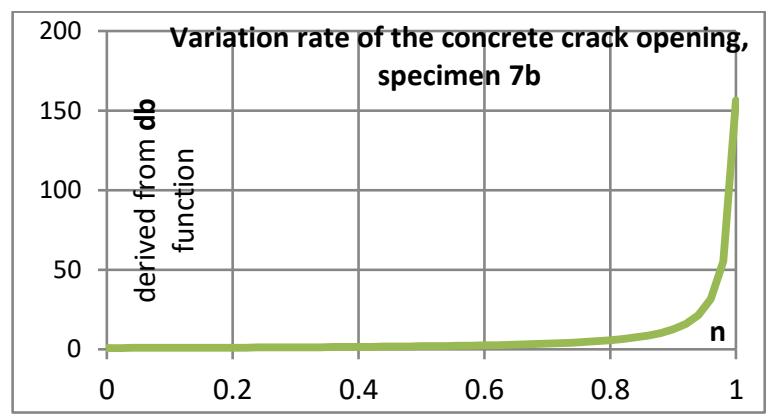

b. specimen $7 b$

Figure 15 Variation rate of the concrete crack opening, specimen $7 \mathrm{a}$ and $7 \mathrm{~b}$

- a proportional and slightly different increase, in the case of analyzing the parameters related to the crack length $(f)$, but also in case the crack opening in the pre-cracked concrete support layer also varies (Figure 15), considering an evolution of the load-bearing capacity reduction of the foundation layers of 
such a road structure.

- there is practically a proportional variation of all the parameters analyzed on $2 / 3$ of the asphalt layer thickness, after which in the last third, the propagation speed of the reflective crack shows an increase in the plastic stage before the rupture, when the crack appears at the surface of the layer asphalt.

If a multiparametric analysis is taken into account, resulting from the overlap of the variation of the propagation speed of the reflective crack, through the evolution of each analyzed parameter, respectively the opening of the crack in the pre-cracked concrete support layer $(d b)$, the implicit opening at the base of the asphalt layer $(d)$, and the propagation of the crack length $(f)$ on the thickness of the asphalt layer, all related to the cyclical evolution of the loads assimilated to road traffic, results in a multicriteria variation diagram (Figure 16).

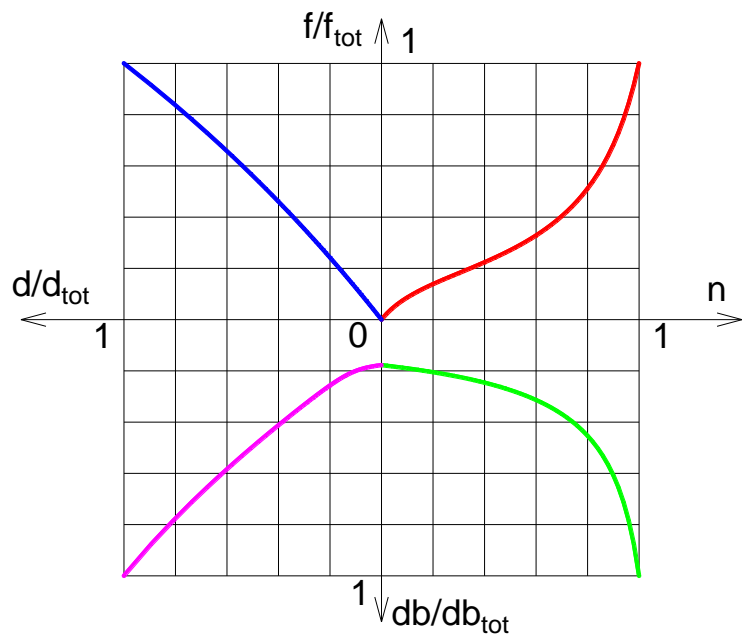

Figure 16 Multicriteria variation diagram of the 4 parameters

All these experimental findings, transposed for phenomenological explanation in mathematical modeling, can find practical use, in the case of applying an extensive research program, on several types of asphalt road materials used as variants of execution to the asphalt protection layer of a concrete pavement degraded during the operation period.

\section{CONCLUSIONS}

The results of the experimental modeling on the Cracking Device with Temperature Control can be expressed using a mathematical model, more precisely regression functions that describe the variations of the cracking parameters, depending on what is desired: 
- The length of the crack depending on the number of cycles - we can determine the time in which the crack propagates on half the thickness of the protective layer. This finding is extremely important in relation to other experimental models used in the evaluation of the fatigue phenomenon in the asphalt layers, which establish that the strength of the layer is consumed if half of the deformation accumulated during the stress cycles has been consumed.

- Calculating the variation rate of the existing crack opening in the concrete support layer, the phenomenon created by the transfer effect to the crack by the initial friction of the walls of this support layer is highlighted, attenuated by the damping of the transfer process of the concrete layer, which function together with it by applying the technological priming operation. Thus, initially, when the transfer from the crack of the concrete works together with the damping of the asphalt layer present at its surface, the capacity to take over the vertical deformation is higher and therefore the opening speed of the existing crack in the concrete is smaller.

- In the intermediate stage, when the transfer of the concrete crack is consumed, the transfer capacity of the asphalt is mobilized. The curvature of the diagram changes, so that in the final phase of reflective propagation the crack opening speed of concrete to grow at a lower deflection.

\section{REFERENCES}

[1] Anderson, T. L. (2005). Fracture Mechanics: Fundamentals and Applications, Third Edition. CRC Press.

[2] Elseifi, M. A., \& Al-Qadi, I. L. (2004). A Simplified Overlay Design Model against Reflective Cracking Utilizing Service Life Prediction. Road Materials and Pavement Design, 5(2), 169-191. doi:10.1080/14680629.2004.9689968

[3] Griffith, A. A. (1921). The phenomena of rupture and flow in solids. 221(582-593), 163-198.

[4] Irwin, G., \& Kies, J. (1952). Fracturing and Fracture Dynamics. Welding Journal Research Supplement.

[5] Irwin, G., \& Kies, J. (1954). Critical Energy rate analysis of fracture strength of large welded structures. The Welding Journal Research Supplement. 


\section{ROMANIAN JOURNAL \\ OF TRANSPORT INFRASTRUCTURE}

Mihai Gabriel Lobază

Accelerated laboratory testing for reflective cracking

[6] Lobază, M. G. (2020). Contributions regarding the analysis by modeling the rehabilitated road structures at loads assimilated to road traffic. $\mathrm{PhD}$ Thesis, Technical University of Civil Engineering, Bucharest.

[7] Lobază, M. G., \& Dicu, M. (2013, July 4-5). Anticipating the cracking process of asphalt pavements by experimental modeling in the laboratory. Road Research and Administration, VI-th Edition, (pp. 291-302). Bucharest.

[8] Lobază, M. G., \& Dicu, M. (2015, July). Experimental Modelling of Asphaltic Layers Behaviour at Reflective Fracture from Degraded Pavements - Parametric Studies. Romanian Journal of Transport Infrastructure, 4(1), 56-66. doi:https://doi.org/10.1515/rjti-2015-0031

[9] Perez, S., Balay, J., Tamagny, P., \& Petit, C. (2007, December). Accelerated pavement testing and modeling of reflective cracking in pavements. Engineering Failure Analysis, 14(8), 1526-1537. Retrieved from https://doi.org/10.1016/j.engfailanal.2006.12.010

[10] Perraton, D., Guissi, G., Pierre, P., \& Dore, G. (2008). A new laboratory test for reflective cracking in mode I and/or mode II. Proceedings of the 6th RILEM International Conference on Cracking in Pavements. Chigago, USA.

[11] Ramsamooj, D., \& Majidzadeh, K. (1973). Mechanistic Approach to the solution of cracking in pavements. California: National Reseach Council, Highway Research Board.

[12] Yu, B., Lu, Q., \& Yang, J. (2013). Evaluation of anti-reflective cracking. International Journal of Pavement Engineering, 14(6), 553-560. doi:10.1080/10298436.2012.721547 